\title{
Editorial
}

\section{Cuerpos diversos: Propender por la integración social de las personas transexuales}

\author{
José Miguel Silva Herrera1 ${ }^{10}$ \\ ${ }^{1}$ Facultad de Medicina, Pontificia Universidad Javeriana, Urólogo, \\ Unidad de Urología, Hospital Universitario San Ignacio, Bogotá DC, \\ Colombia
}

Urol Colomb 2021;30(4):e225-e226.

Es notable el giro conceptual que ha demostrado la sociedad en general para permitir la integración de las personas transexuales en distintos ámbitos, esto, con el menor maltrato posible. Especialmente en lo corrido del siglo XXI disciplinas tales como el derecho, la psicología, la antropología y sociología, al igual que la medicina y las profesiones afines han hecho aportes graduales y trascendentes que han permitido entender mejor la condición.

Por otro lado, los diferentes grupos de presión originados en las múltiples organizaciones LGBTI son cada vez mas visibles e influyentes en todas las latitudes, con diferentes grados de preponderancia según las circunstancias ideológicas y sociopolíticas de los países. Estas organizaciones han influido en la protección de los derechos a través de leyes de identidad de género y antidiscriminación.

La comunidad médica es consciente de que aún existe un enorme déficit en los programas de formación general y especializada para mejorar la comprensión del tema en el personal de salud que redunde en una atención más oportuna y centrada en las necesidades individuales producto de la diversidad sexual. Aunque ya se han superado conceptos anacrónicos como el de enfermedad mental y también confusiones con travestismo u homosexualismo, es necesario desmontar el modelo binario que contempla exclusivamente dos sexos, dos géneros y dos identidades, el que además exige, que coincidan en todos los casos. Asimismo, hoy es mas evidente que no se debe centrar la atención solamente en función del tránsito y la reasignación genital.

Desde la segunda mitad del siglo XX se constituyeron grupos multidisciplinarios para la atención médica integral de las personas transgénero y, con ellos, se establecieron condiciones mínimas para las intervenciones medicamentosas y quirúrgicas. De igual forma, estos términos se han flexibilizado con el tiempo en la medida que el entorno familiar y social de estas personas impone menos obstáculos y facilita una temprana aceptación y expresión de la identidad de género deseada.

La tendencia global de los centros especializados en la atención de personas transexuales se dirige cada vez más a incluir menores de edad, basados en el reconocimiento de que desde la infancia temprana, entre dos y tres años, se producen claras señales persistentes de identificación sexual. Es así como, en clínicas especializadas en el tema transexual, entre los que se destaca el grupo del Hospital Universitario Ramón y Cajal de Madrid, se detecta una población pediátrica creciente, que supera ya el $5 \%{ }^{1}$

El apoyo temprano de los niños cuya identidad sexual no corresponde con el sexo biológico es una forma de mantener la autoestima y disminuir los trastornos de comportamiento, de aprendizaje, depresión, y todos aquellos problemas mentales originados en el sufrimiento persistente. Se ha detectado también alto riesgo de suicidio, producto de los problemas que surgen al enfrentar a la familia, los amigos y el ambiente escolar.

La legislación en algunos países ayuda al facilitar el cambio de nombre y de sexo en los documentos de identidad. En la evaluación médica necesaria para proceder con el tránsito de la población infantil, hay una tendencia clara a basarse en la historia de vida, casi como la única prueba requerida de dicha condición inmutable.

Profundizar en el conocimiento del tema e incrementar las competencias, son necesidades que tiene el urólogo actual, por cuanto se puede ver enfrentado a la consulta desde diferentes ramas de la especialidad. En ese momento, deberá orientar a los padres en atender las señales que se suelen desprender de las manifestaciones de los roles de género, en algunas oportunidades exageradas y estereotipadas; para actuar a tiempo y facilitar un tránsito social respetuoso, tolerante, sin
Address for correspondence José Miguel Silva Herrera, MD, MSc, Profesor asociado, Facultad de Medicina, Pontificia Universidad Javeriana, Urólogo, Unidad de Urología, Hospital Universitario San Ignacio, Bogotá DC, Colombia

(e-mail: jose.silva@javeriana.edu.co).
DOI https://doi.org/ 10.1055/s-0041-1740543. ISSN $0120-789 X$. e ISSN 2027-0119.

$$
\text { (n) }
$$

\footnotetext{
(c) 2021. Sociedad Colombiana de Urología. All rights reserved. This is an open access article published by Thieme under the terms of the Creative Commons Attribution-NonDerivative-NonCommercial-License, permitting copying and reproduction so long as the original work is given appropriate credit. Contents may not be used for commercial purposes, or adapted, remixed, transformed or built upon. (https://creativecommons.org/ licenses/by-nc-nd/4.0/) Thieme Revinter Publicações Ltda., Rua do Matoso 170, Rio de Janeiro, RJ, CEP 20270-135, Brazil
} 
maltrato ni opresión, que permita aminorar el sufrimiento y las consecuencias psicológicas que este acarrea.

Conflictos de Interés

El autor no declara conflictos de interés.

\section{Referencia}

1 ElDiario.es. (2017, August 13). La Unidad de Género del Hospital Ramón y Cajal cumple 10 años "con orgullo". ElDiario.es. Retrieved November 1, 2021, from https://www.eldiario.es/sociedad/unidadgenero-hospital-ramon_1_3239279.html 